\title{
Development of a Java-based application for environmental remote sensing data processing
}

\author{
Badr-eddine Boudriki Semlali ${ }^{1}$, Chaker El Amrani ${ }^{2}$, Siegfried Denys ${ }^{3}$ \\ 1,2Laboratory of Informatics, Systems and Telecommunications, Department of Computer Engineering, \\ Faculty of science and technology, Abdelmalek Essaâdi University, Morocco \\ ${ }^{3}$ Sustainable Energy, Air \& Water Technology, Department of Bioscience Engineering, University of Antwerp, \\ Groenenborgerlaan 171, B-2020 Antwerp, Belgium
}

\begin{tabular}{|c|c|}
\hline Article Info & ABSTRACT \\
\hline Article history: & Air pollution is one of the most serious problems the world faces today. It is \\
\hline Received Jun 12, 2018 & $\begin{array}{l}\text { highly necessary to monitor pollutants in real-time to anticipate and reduce } \\
\text { damages caused in several fields of activities. Likewise, it is necessary to }\end{array}$ \\
\hline Revised Nov 22, 2018 & provide decision makers with useful and updated environmental data. As a \\
\hline Accepted Dec 18, 2018 & $\begin{array}{l}\text { solution to a part of the above-mentioned necessities, we developed a Java- } \\
\text { based application software to collect, process and visualize several }\end{array}$ \\
\hline Keywords: & $\begin{array}{l}\text { environmental and pollution data, acquired from the Mediterranean Dialog } \\
\text { earth Observatory (MDEO) platform [1]. This application will amass data of }\end{array}$ \\
\hline $\begin{array}{l}\text { Air pollution } \\
\text { Interactive environmental map } \\
\text { Remote sensing }\end{array}$ & $\begin{array}{l}\text { Morocco area from EUMETSAT satellites, and will decompress, filter and } \\
\text { classify the received datasets. Then we will use the processed data to build an } \\
\text { interactive environmental real-time map of Morocco. This should help } \\
\text { finding out potential correlations between pollutants and emitting sources. }\end{array}$ \\
\hline Satellite sensors & \\
\hline
\end{tabular}

Copyright (C) 2019 Institute of Advanced Engineering and Science. All rights reserved.

\section{Corresponding Author:}

Badr-Eddine Boudriki Semlali,

Department of Computer Engineering,

Abdelmalek Essaadi University of Tangier,

Ancienne Route de l'Aéroport, Km 10, Ziaten. BP: 416. Tanger - Morocco.

Email: badreddine.boudrikisemlali@uae.ac.ma

\section{INTRODUCTION}

Nowadays we are witnessing important climate and environmental changes in temperature, rainfall and air quality. This is mainly due to industrial, residential, and agriculture activities, and to road and maritime transport which generate unhealthy and even toxic gases like $\mathrm{CO}, \mathrm{NO}_{\mathrm{x}}, \mathrm{VOC}$ 's and particulate matter (PM). The World Health Organization (WHO) confirms that about 3 millions of deaths per year are caused by daily exposure to pollution [2].

It is therefore highly recommended to monitor, in real-time, environmental and air pollution data. Real time monitoring can facilitate early warning and mitigation of a wide range of biogenic and anthropogenic disasters using remote sensing techniques That mean an acquisition of information about an object without making a physical contact with it, generally remote sensing refers to the satellite or aircraft based sensors to measure various variable of earth and atmosphere. Sensor are defined as instrument that measure different radiation, light wavelengths reflected or scattered from earth surface or atmosphere compounds [3]. Some examples of these disasters are flooding, storms, forest fires, climate change, and recent public health incidents, such as malaria and avian influenza. Obviously, also for the mitigation of air pollution it is necessary to analyze air quality data and apply appropriate methods to purify air, particularly in urban zones.

Satellites are the best choice to retrieve environmental and pollution data in real-time with a global covering of glob. The European Organization for the Exploitation of Meteorological Satellites (EUMETSAT) supplies weather and climate-related satellite data, images and products 24 hours a day, 365 days a year to 
the National Meteorological Services of Member and Cooperating States in Europe, and other users worldwide. In this way, EUMETSAT helps to detect and capture climate information, oceanic monitoring, and observation of air quality continuously throughout the year. Many countries from Europe and Africa have full access to EUMETSAT data which helps to supervise the climate and take appropriate and rapid actions against biogenic and anthropogenic disasters [4]. This can help decision makers taking adequate actions to prevent and mitigate serious problems. Unfortunately, data acquired from satellites are very big and complex, which makes it difficult to process them manually. The proposed solution that may contribute in problem's solving is to develop an application that automatically downloads, filters, subsets and visualizes data received from satellites. In this study, we present a Java-based application to process and visualize data retrieved from EUMETSAT's currently operational satellites Metop and Meteosat Second Generation (MSG) [5]. Data are acquired from the Mediterranean Dialogue Earth Observatory (MDEO) platform, comprising a real-time satellite remote sensing ground station installed at Abdelmalek Essadi University, post processing computer clusters and relevant storage, software and distributional network. "Source: paper published at IGARSS2013 conference [1]. This study is part of a VLIR-UOS funded project entitled: Outdoor Air Quality Monitoring in Morocco and Purification Processes [6], the objective of this paper is to answers to several questions like: how can remote sensing help in weather forecasting? How to use satellite data to depict environmental and pollutants values in Morocco? How to correlate between data collected from satellites and emitting sources in Morocco? especially factories, thermal power plants and traffic.

\section{MATERIALS AND METHODS}

In this research, we have used data received from polar MetOp satellites and the geostationary Meteosat Second Generation (MSG) satellites. Polar satellites pass over both poles of the earth by an orbit designed to ensure that the angle between the orbital plane and the sun remains constant. MetOp Satellites move in a particular orbit with an Altitude of $850 \mathrm{Km}$ from earth, taking $100 \mathrm{~min}$ time. The scanned surface per orbit is $3000 \mathrm{~km} 2$ at 14 orbits per day and it takes 29 days to completely scan the Earth. Sensors used in this study are Infrared Atmospheric Sounding Interferometer (IASI), which measure temperature, humidity and ozone density in cloud conditions and calculate the Vertical Column Density (VCD) that represents the total amount of molecules over vertical slices [7]. We have also used the Advanced Microwave Sounding Unit (AMSU), sensor that captures temperature changes, atmospheric humidity and soil moisture.

The second satellite series, Meteosat Second Generation (MSG), operates over Europe, Africa and the Indian Ocean at an altitude of $36,000 \mathrm{~km}$. They provide variables like temperature, humidity and pressure in near real time. MSG is spin-stabilized and capable of greatly-enhanced Earth observations. The satellite's 12-channel SEVIRI imager observes the half part of the Earth with an unprecedented repeat cycle of 15 minutes in 12 spectral wavelength regions or channels [8].

\section{ACQUISITION OF MDEO DATA AND THE PROPOSED JAVA APPLICATION FOR PROCESSING}

EUMETCast is a multi-service dissemination system based on multicast technology and it uses MetOp A and B satellites equipped with appropriate sensors [7]. Within this protocol, information measured by the last orbit of MetOp are transferred to the Central Data Acquisition (CDA), located in Svalbard (North Pole) and Antarctica (South Pole), information's gained on these two stations are transferred to the Central Facility (CF) in Germany which generate data of level 1 and 2. Finally global or regional services provides to end-users data in near real and near-real time [6] as shown in Figure 1.

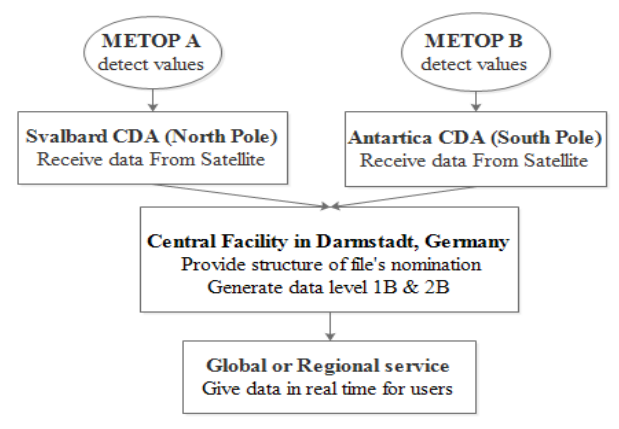

Figure 1. Global or regional services 


\subsection{Acquisition of data}

Mediterranean Dialog Earth Observatory (MDEO) platform provides data from polar satellites like MetOp and JASON, also from geostationary satellite like Meteosat Second Generation (MSG). Data retrieved are formatted differently. BUFR, Binary and NetCDF files formats are the most used in our study. This application downloads data automatically from EUMETCast service using a bash script to connect with the FTP server, among the benefits of EUMETCast, it makes a secure broadcast with target one or a group of users, encrypt data and support DVB-S2 receiver [9]. We exploit in this study, the receiver station of Abdelmalek Essaadi University, Figure 2, to get MetOp and Meteosat data. Data have 2 formats, binary or BUFR. EUMETSAT use a specified structure of file's name applied by the World Meteorological Organization (WMO) that enables to identify and process files quite easily [1]-[5].
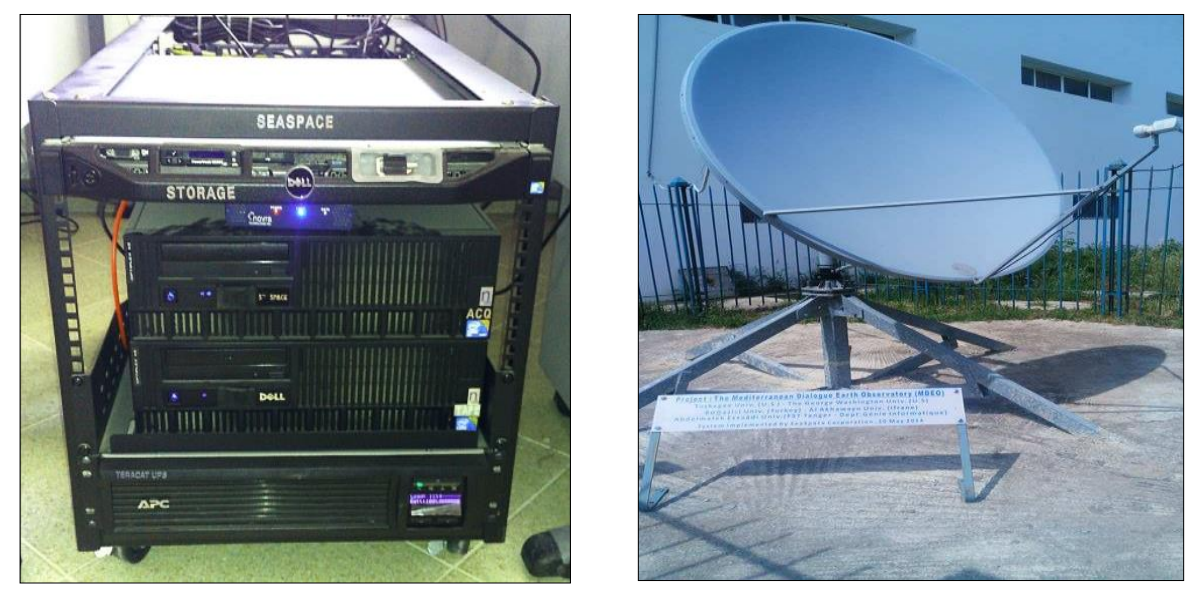

Figure 2. MDEO ground station and cluster at Abdelmalek Essaadi University

Files acquired from the satellite have different formats; however in this study we exploited 3 files format, the first is BUFR (Binary Universal Form for the Representation of meteorological data), it is widely used even in satellite meteorology. The format is used mostly for satellite sounder data, like AMSU and MHS and MetOp IASI, the latest version is BUFR Edition 4. The second format is The Network Common Data (NetCDF), it is a data format, and programming interfaces that helps read and write scientific data. The NetCDF format is composed of variables, dimensions and attributes. The third format is The Hierarchical Data Format (HDF5) that stores and structures very large amounts of data, the HDF5 Supports Scientifics data, and is fast in storage also independent of the platform.

\subsection{Java-based application software}

Data acquired from satellites are very big and complex, and it is difficult to process them manually, so we developed a java-based application that automatically downloads, filters, subsets and visualizes data of the studied zone.The accomplishment of this application was compiled under Linux OS with DEBIAN (Jessie Distribution). Java was the Programming language applied because it supports a wide range of Application Programming Interfaces (API) and supports Thread that can be helpful to process hard operations. To visualize data in maps, we used Folium and Matplotlib from Python library; in addition we used Bash language to manipulate data and different files. We installed other supplementary libraries, especially CURL, ZLIB, Numpy, NetCDF and HDF5 library [6],[10]-[12], to complete the execution of this application.

Data collected from EUMETSAT Satellite covers large zones. For our purpose, only data of Morocco will be retained and studied. This application makes available an automatic decompression of downloaded files. Afterward Files will be classified by orbits number inside new generated folders. Next step is to subset these datasets to Morocco area. So we had to identify the orbits covering this zone. We found that there are two to four orbits per day flying over the country. Then data of Morocco will be sorted by date in new folders. Therefore the developed application will refine files covering Morocco zone inside another new folder named "Morocco_filtered". The binary and BUFR collected files are converted to CSV format to become readable. Finally the Java application automatically generates files including values of temperatures, pressures, and Vertical Column Density (VCD) of $\mathrm{CO}_{2}, \mathrm{CO}, \mathrm{NO}_{2}$. 


\section{VISUALIZATION OF MDEO DATA}

As a result, all environmental and pollutants values of Morocco are available, the developed application will plot them in near-real time into interactive map and chart.

\subsection{Map visualization}

MetOp data are represented on the map using a special Python library called Folium [13]. Datasets represented are those related to Tangier, North Region, and Morocco. We got about 4000 datasets per 24 hours, providing 4000 possible plots. The distance between two plotted points is $10 \mathrm{Km}$. a basic interpolation algorithm was applied to the datasets. In order to fill the gaps with approximate values [10], in the same maps , locations of anthropogenic pollution sources, such as thermals power plants, factories, ports, etc were represented to helps decision-makers find correlations between atmospheric emissions and industrial activities. NetCDF downloaded files are plotted using Matplotlib python.

Figure 3 to Figure 6, show respectively average values of temperature, humidity, wind speed and pressure in Morocco, on the first May 2017. Data are received from MetOp satellites with IASI sensor. Temperature is lower in coastal zones, and humidity is higher in central areas like in Ifrane and Marrakech. Wind speed varies between 3 and $38 \mathrm{Km} / \mathrm{h}$ and pressure between 0.9 and $1.1 \mathrm{Atm}$.

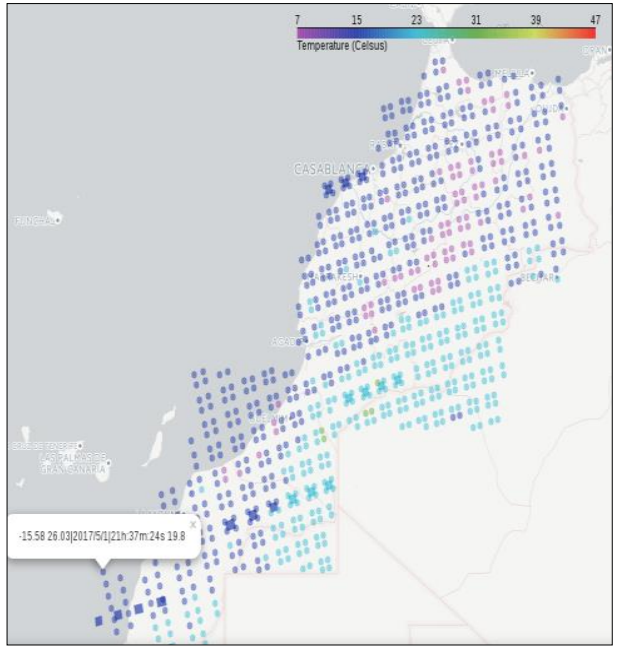

Figure 3. Temperature

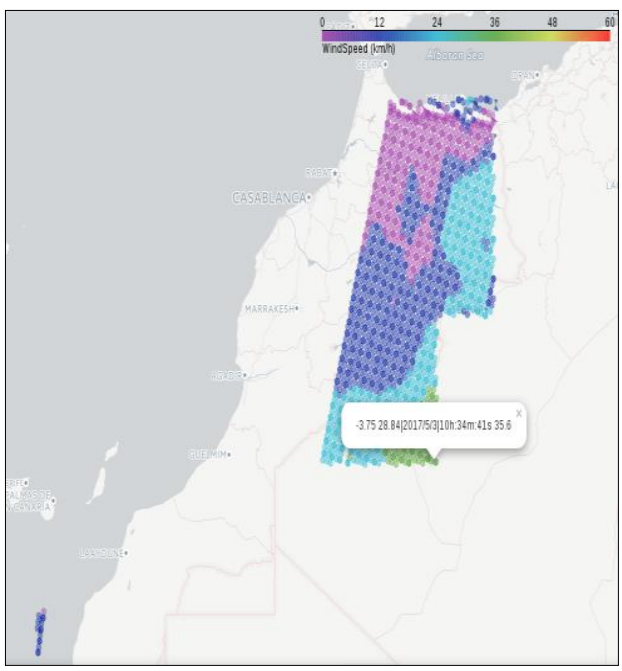

Figure 5. Wind speed

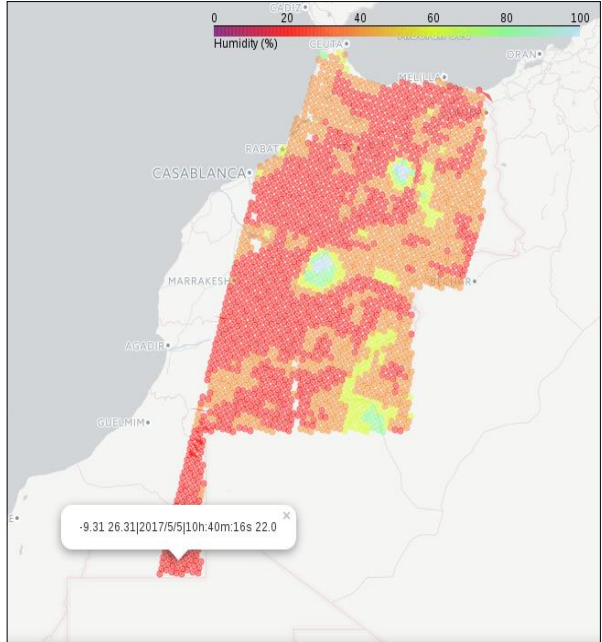

Figure 4. Humidity

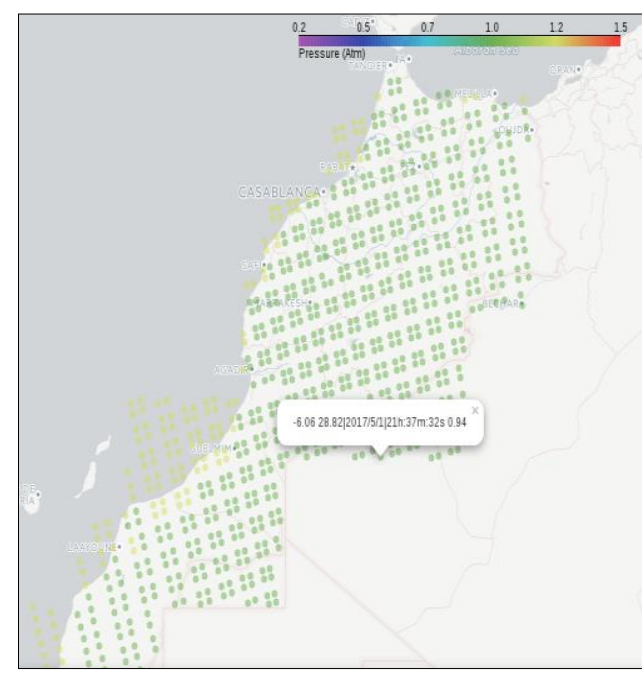

Figure 6. Pressure 


\subsection{Chart visualization}

Tree kinds of chart were designed within the program. The acquired remote sensing datasets were compared to data collected from ground sensors as shown in Figure 7.

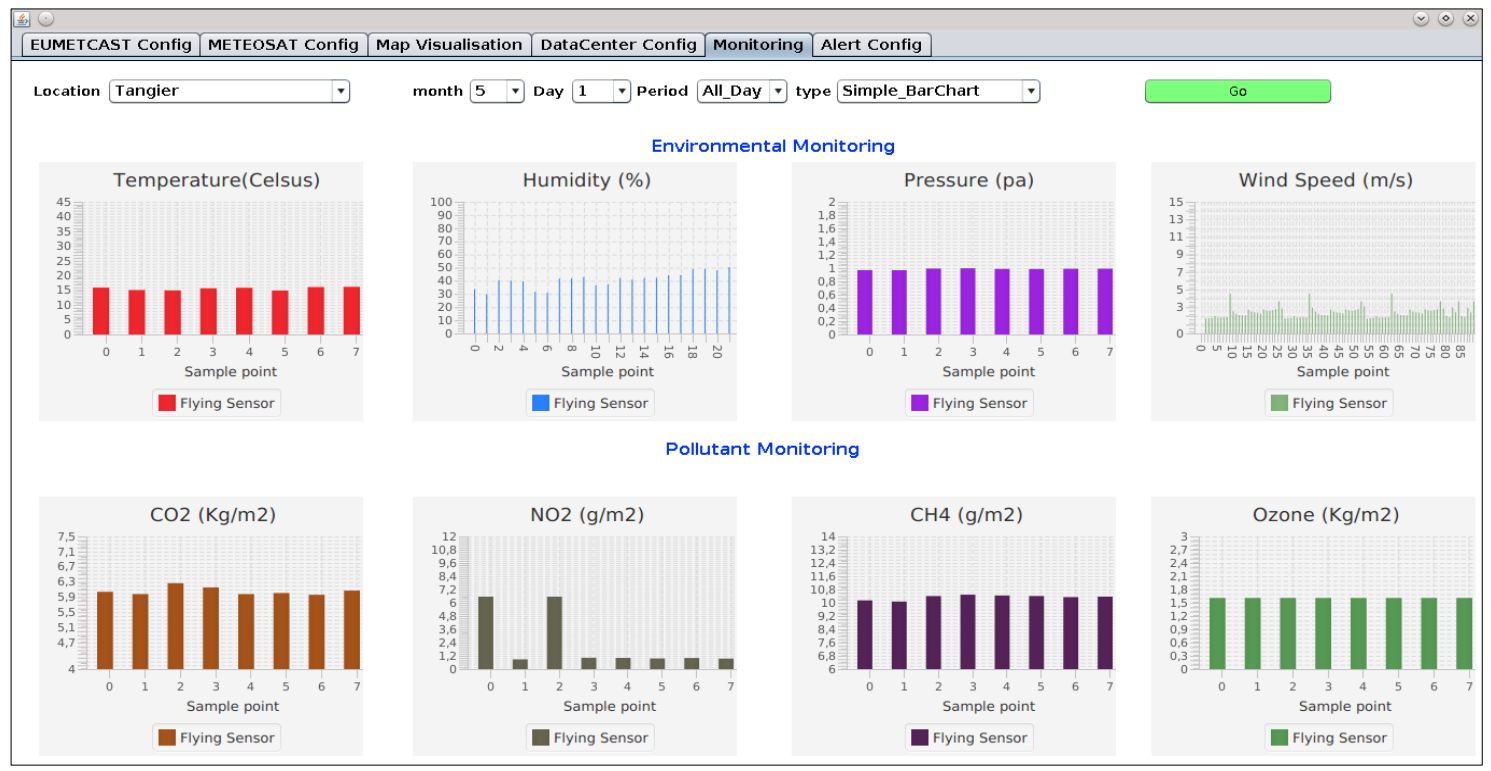

Figure 7. Simple bar chart of 2017/05/01 in tangier

\section{RESULTS AND DISCUSSION}

Air pollution refers to the contamination of air and can further be classed into several kinds, visible or invisible categories. This is due to industrial, agricultural and transport activities. Air pollution is one of the major hazards in urban centers of the world; it has the most direct quality impact on human lives, causing serious diseases, especially respiratory and heart problems due to emissions of harmful gases like Nitrogenous dioxide $\left(\mathrm{NO}_{2}\right)$ and Sulfur dioxide $\left(\mathrm{SO}_{2}\right)$. There are also other consequences of air pollution; particularly global warming and the depletion of ozone layer which is responsible for protecting humans from dangerous Ultraviolet (UV).

There are 2 types of air pollution gases. The first one has greenhouse effect participates and result in changing the climate, and the second one is about toxic gases threaten human health [3]. Most cities worldwide suffer from important air quality problems produced from the burning of fossils fuels, emitted by maritime and air transport. Industrial activities are behind the release of important amount of Carbon monoxide (CO).the thermal power plants are producing height concentration of Carbone Dioxide $\left(\mathrm{CO}_{2}\right)$, Sulfur dioxide $\left(\mathrm{SO}_{2}\right)$ and Nitrogenous Oxide (NOx) [11]. Morocco also undergo from air pollution due to industrials zones located in big cities especially Casablanca, Tangier and Safi. Table 1, Table 2 and Table 3 provide details of several factories, power thermal plants and ports in Morocco. We notice that panting, cement and metallic productions are the most industrial activities in Morocco, particularly in big cities like Casablanca Tangier, and Agadir. In addition, there are five important thermal plants in the country, producing electricity by the use of fossil fuel, which contribute to the pollution of urban air and carbon located in Kenitra, Casablanca and Safi [14].

Table 1. Factories in Morocco

\begin{tabular}{ccccccc}
\hline Name & Activity & City & Longitude & Latitude & Altitude & Intended gases \\
\hline Lafarge & $\begin{array}{c}\text { Production of } \\
\text { cement }\end{array}$ & Casablanca & 33.55 & $-7,53$ & 17 & $\begin{array}{c}\text { PM2,5/10 } \\
\text { SO }\end{array}$ \\
$\begin{array}{c}\text { Production of } \\
\text { painting } \\
\text { METALFER }\end{array}$ & Agadir & 30.41 & $-9,45$ & 17 & $\begin{array}{c}\mathrm{CFC} \\
\mathrm{SO}_{2} \\
\end{array}$ \\
$\begin{array}{c}\text { Metallic } \\
\text { Construction }\end{array}$ & Tangier & 35.71 & $-5,90$ & 17 & $\begin{array}{c}\mathrm{CO} \\
\mathrm{SO}_{2} \\
\mathrm{PM}_{2}, 5 / 10\end{array}$ \\
\hline
\end{tabular}


Table 2. Thermal power plants in Morocco

\begin{tabular}{ccccccc}
\hline Name & Type & City & Longitude & Latitude & Altitude & Intended gas \\
\hline Appy-be & PTP & Mohamadia & 33.86 & $-7,43$ & 15 & $\mathrm{CO}_{2}$ \\
JORF-Al Asfar & PTP & Safi & 33.10 & $-8,63$ & 17 & $\mathrm{SO}_{2}$ \\
Tkc-one & PTP & Kenitra & 33.20 & $-6,56$ & 17 & $\mathrm{NO}_{2}$ \\
CTC & PTP & Casablanca & 33.60 & $-7,57$ & 16 & $\mathrm{CH}_{4}$ \\
OCP & Phosphate & Khouribga & 33.11 & $-8,60$ & 15 & $\mathrm{PM} \mathrm{2.5}^{2.57}$ \\
& mine & & & & $\mathrm{PM} 10^{\mathrm{CO}_{2}}$ \\
\hline
\end{tabular}

Table 3. Ports in Morocco

\begin{tabular}{ccccc}
\hline Name & Longitude & Latitude & Altitude & Intended gas \\
\hline Saidia port & 35.11 & -2.29 & 17 & \\
TangerMed port & 35.88 & $-5,49$ & 17 & $\mathrm{CO}_{2}$ \\
Casablanaca port & 33.57 & $-7,74$ & 13 & $\mathrm{NO}_{2}$ \\
Agadir Port & 30.42 & $-9,64$ & 5 & $\mathrm{SO}_{2}$ \\
Port Jorf Asfar & 33,35 & $-8,38$ & 10 & \\
\hline
\end{tabular}

This study tries to show a clear correlation between concentration of air pollution and emitting origins in Morocco. These practices are based upon monitoring some gases like $\mathrm{CO}_{2}, \mathrm{NO}_{2}, \mathrm{CH}_{4}$ and Ozone surrounding industrials cities especially Casablanca, Tangier and Safi. We will study and discuss 4 scenarios as follows.

\subsection{Scenario 1: impact of factories in air pollution}

Factories one a major source of air pollution, through fossil fuel emission. Emissions include Carbon Dioxide (CO) and Methane (CH4). In Morocco there are several factories located in Casablanca and Tangier producing and processing metal, plastic, cement and painting products. In the map below, Figure 8 and Figure 9, we can observe high density of $\mathrm{CO}_{2}$ and $\mathrm{CO}$ concentration nearby these industrial areas.

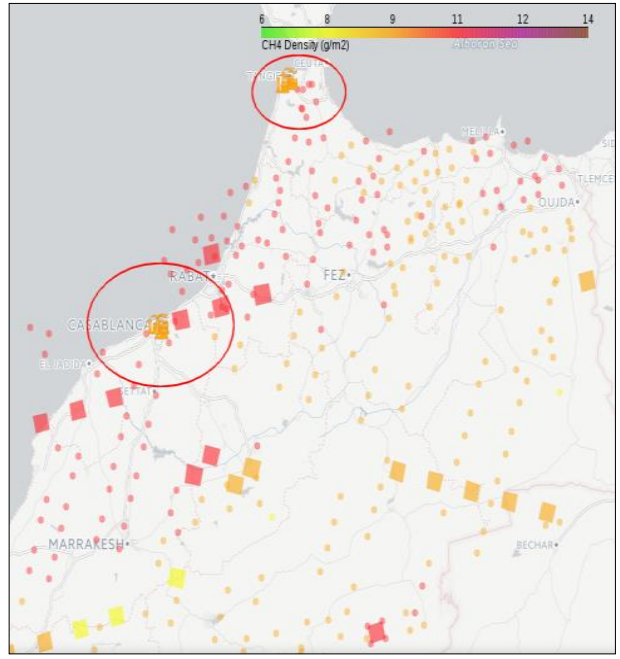

Figure 8. $\mathrm{CO}_{2}$ densities of $2017 / 07 / 16$ at $10 \mathrm{~h}$ in Morocco with plot of factories

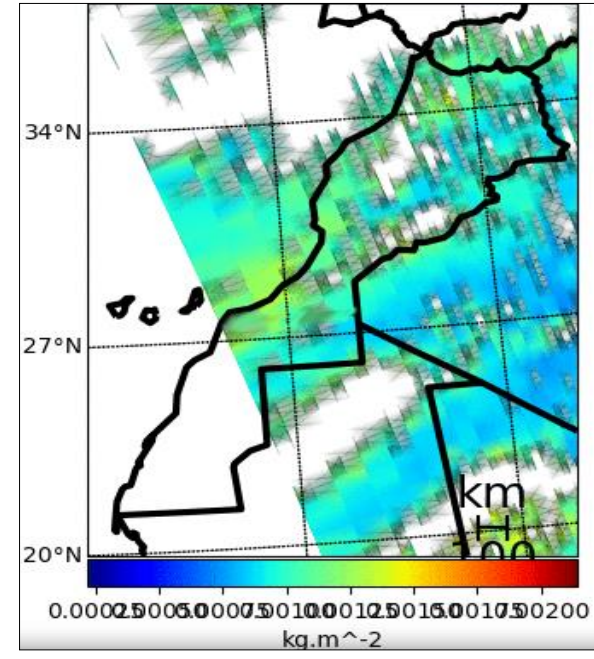

Figure 9. CO densities of 2017/04/27 at 20h in Morocco

\subsection{Scenario 2: impact of thermal power plants in air pollution:}

Burning Coal in a power plant is highly polluting. Some resulting pollutants are specific to the type of fuel is part of the combustion process or is related to the design and configuration of the plant. Among pollutants discharged from power plants there are $\mathrm{CO}_{2}$ and $\mathrm{NO}_{2}$. In Morocco we have five thermal plants located in Kenitra, Casablanca, and Khouribga city. They produce electricity using carbon or fossil fuel coal energies. In Figure 10 and Figure 11, we notice an important density of $\mathrm{CO}_{2}, \mathrm{NO}_{2}$ and $\mathrm{CO}$ upper than main values in areas far from the plants zones. 


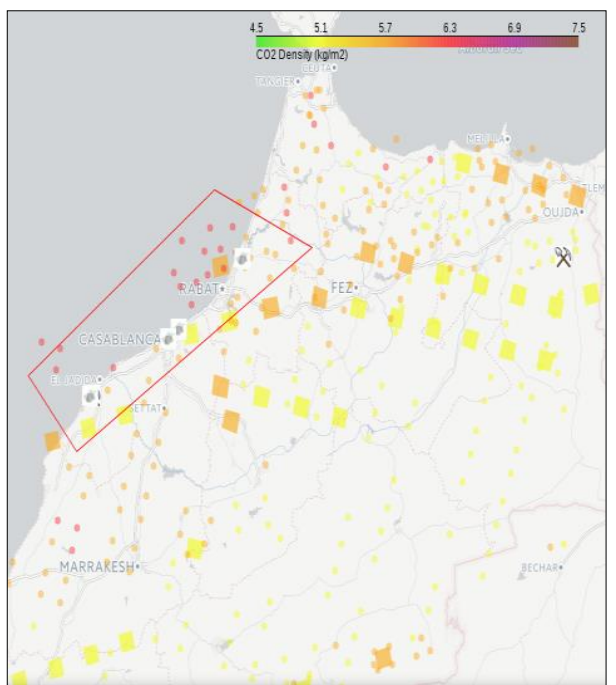

Figure 10. $\mathrm{CO}_{2}$ densities of $2017 / 07 / 18$ at $10 \mathrm{~h}$ in Morocco with PTP

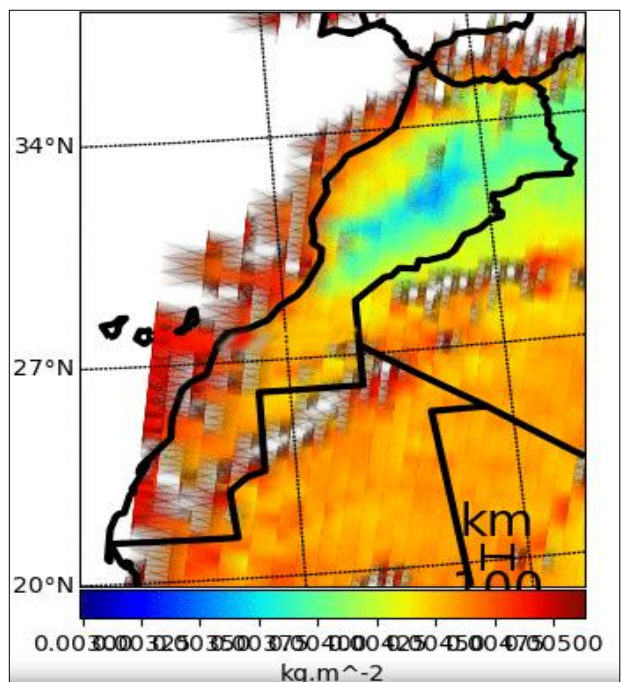

Figure 11. $\mathrm{NO}_{2}$ densities of 2017/04/27 at $10 \mathrm{~h}$ in Morocco

\subsection{Scenario 3: impact of port and fishing village in air pollution}

In cities near ports and coastal areas there are sources of air pollution as well. These sources are ship traffic and fishing villages. Figure 12 and Figure 13, shows a high density of $\mathrm{CO}_{2}, \mathrm{NO} 2$, and $\mathrm{CO}$ gases near the ports, especially in the middle coast that has an important daily maritime transport.

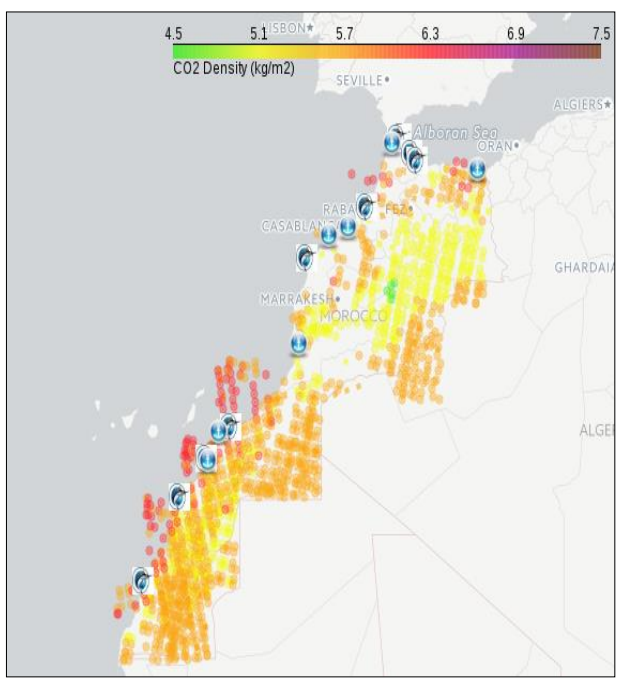

Figure 12. $\mathrm{CO}_{2}$ densities of $2017 / 07 / 17$ at $10 \mathrm{~h}$ in Morocco with plot of ports

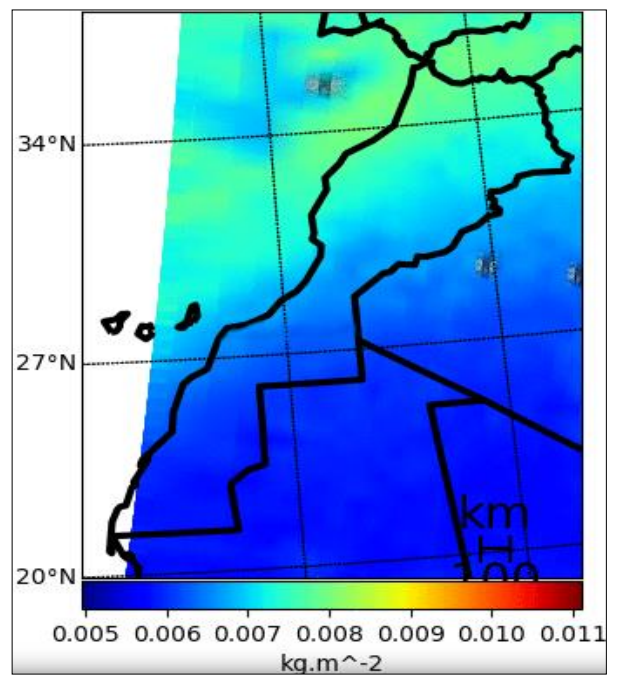

Figure 13. Ozone densities of 2017/04/27 at 20h in Morocco

\subsection{Scenario 4: Impact of dump in air pollution:}

Pollution due to garbage processing is significant in cities particularly if there are no appropriate systems for garbage collection. It is one of the pollution sources because emissions affect directly the human health. In Morocco there are ten big dumps located in Casablanca, Tangier, and Safi. Near these dumps Figure 14 and Figure 15 shows high values of $\mathrm{CO}, \mathrm{CO}_{2}$, and $\mathrm{NO}_{2}$ due to burning garbage. 


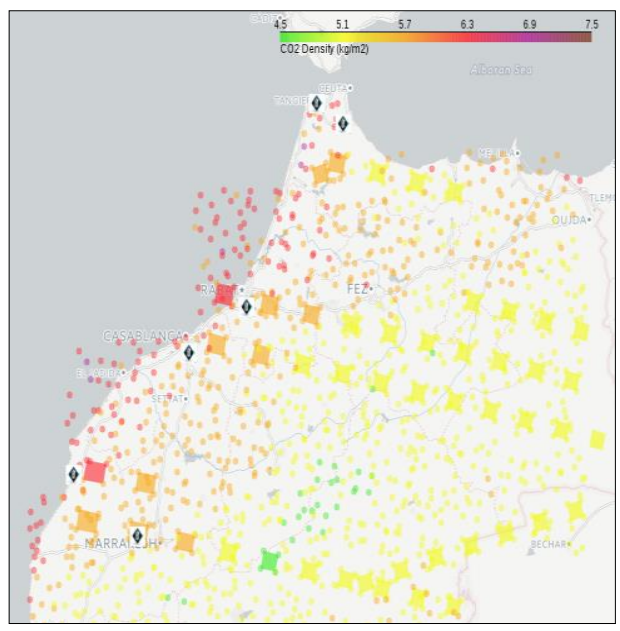

Figure 14. $\mathrm{CO}_{2}$ densities of $2017 / 05 / 4$ at $21 \mathrm{~h}$ in Morocco with plot of dumps

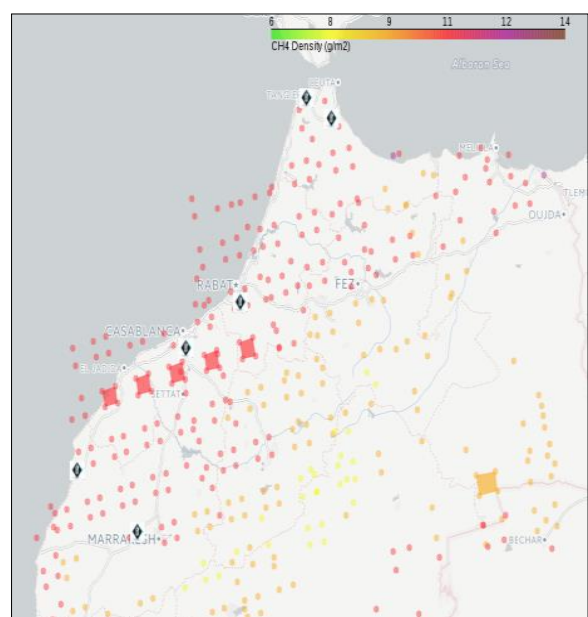

Figure $15 . \mathrm{CH}_{4}$ densities of $2017 / 05 / 4$ at $21 \mathrm{~h}$ in Morocco with plot of dumps

\section{CONCLUSIONS}

Environmental and pollution variables should be continuously monitored by satellites, so to contribute to preventing citizens and assets from environmental disasters. In this paper we focused on air pollution monitoring.In this study we developed a remote sensing system based on data from polar satellites (MetOp) and geostationary satellites (Meteosat) using EUMETCast service. Data were acquired and processed with a Java-based application. An interactive map of Morocco, showing real-time values of environmental and pollution datasets was designed and developed using Python libraries. The application implemented show different locations of industrials activities, and related densities of emitted gases. The application was able to get and process data in real and near-real time, also visualize results in figures and specific charts. Emission from these areas, shows on the map, may affect the neighboring zones, which include cities and villages. These results may be used by decision makers to find adequate solution to adapt to the emitted pollution related potential problems.

\section{ACKNOWLEDGEMENT}

The authors of this work are thankful to VLIR-UOS for the financial support provided within the project ZEIN $2016 Z 193$.

\section{REFERENCES}

[1] El Amrani C., et al., "Development of a real-time urban remote sensing initiative in the mediterranean region for early warning and mitigation of disasters," IEEE, pp. 2782-5, 2012.

[2] Smith K. R., et al., "Millions Dead: How Do We Know and What Does It Mean? Methods Used in the Comparative Risk Assessment of Household Air Pollution," Annu Rev Public Health, vol. 35, pp. 185-206, 2014.

[3] Dewanti D. R., et al., "A Minimum Cloud Cover Mosaic Image Model of the Operational Land Imager Landsat-8 Multitemporal Data using Tile based," Int J Electr Comput Eng (IJECE), vol. 8, pp. 360, 2018.

[4] Schulz J., et al., "Operational climate monitoring from space: the EUMETSAT Satellite Application Facility on Climate Monitoring (CM-SAF)," Atmos Chem Phys., pp. 23, 2009.

[5] Aminou D. M. A., "MSG Project, ESA Directorate of Earth Observation," ESTEC, Noordwijk, The Netherlands.

[6] EUMETCast, "EUMETSAT," $\quad$ Eumetsat.int., $2018 . \quad$ Available https://www.eumetsat.int/website/home/Data/DataDelivery/EUMETCast/index.html

[7] Boynard A., et al., "Measurements of total and tropospheric ozone from IASI: comparison with correlative satellite, ground-based and ozonesonde observations," Atmospheric Chem Phys., vol. 9, pp. 6255-71, 2009.

[8] Schmetz J., et al., "An Introduction to Meteosat Second Generation (MSG)," Bull Am Meteorol Soc., vol. 83, pp. 977-92, 2002.

[9] El Amrani C., et al., "System architecture of the Mediterranean Dialogue Earth Observatory," IEEE, pp. 600-3, 2013. Available from: http://ieeexplore.ieee.org/document/6721228/

[10] Chandana B. S., et al., "Clustering Algorithm Combined with Hill Climbing for Classification of Remote Sensing Image," vol. 4, pp. 8, 2014. 
[11] Duncan B. N., et al., "Satellite data of atmospheric pollution for U.S. air quality applications: Examples of applications, summary of data end-user resources, answers to FAQs, and common mistakes to avoid," Atmos Environ, vol. 94, pp. 647-62, 2014.

[12] Python-visualization/folium, "GitHub," 2018. Available from: https://github.com/python- visualization/folium

[13] Plotting data on a map (Example Gallery) - Basemap Matplotlib Toolkit 1.1.0 documentation [Internet]. Matplotlib.org. 2018 [cited 21 May 2018]. Available from: https://matplotlib.org/basemap/users/examples.html

[14] Annuaire des entreprises Maroc - Morocco tourism and travel- location riad voyage [Internet]. Maroc-adresses.com. 2018 [cited 21 May 2018]. Available from: http://www.maroc-adresses.com/

\section{BIOGRAPHIES OF AUTHORS}
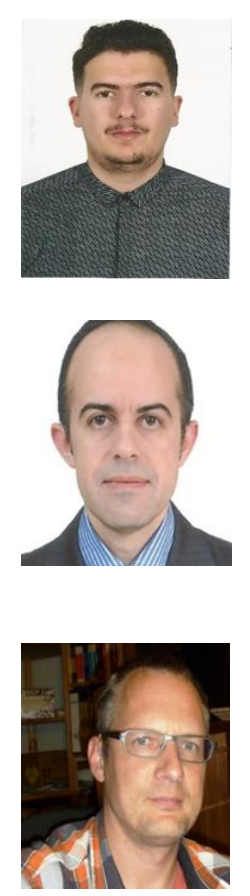

Badreddine Boudriki Semlali Badr-eddine: was born in Tangier, Morocco.He obtained his BSc degrees (2015) from Faculty Sciences and Techniques of Tangier, departement of computer engignering at Abdelmamel Essadi University.Then he got a Master (2017) degrees in Computer System and Network engigniring in the some faculty.Currently he is a researcher in big data analytical of Remently sensing earth observatory.spesclised in Rmote sensing big data collecting, storing and processing, using big data technolgies and cloud computing techniques.

Dr. Chaker El Amrani is Doctor in Mathematical Modelling and Numerical Simulation from the University of Liège, Belgium (2001). He joined Abdelmalek Essaadi University, Morocco in 2003. $\mathrm{He}$ is currently Chair of the Computer Engineering Department at the Faculty of Science and Technology, Tangier. He is the NATO Partner Country Project Director of a real-time remote sensing initiative for early warning and mitigation of disasters and epidemics in Morocco. $\mathrm{He}$ lectures distributed systems and is promoting High Performance Computing education in the University. Dr. El Amrani joined in 2001 Thales Information Systems Company based in Brussels, and worked at Belgocontrol as Air Traffic Control Software Engineer.

Siegfried Denys is a professor at the research group of Sustainable Energy, Air and Water Technology of the University of Antwerp. His expertise is mainly on the development and use of computational models in disciplines (air purification devices, agriculture, chemical engineering and food conservation and technology). The main focus of his current research is sustainable air purification using either advanced, emerging technologies or eco-technological solutions (using microorganisms or urban green. 